\title{
Effect of Waste Mint in Urea Formaldehyde Adhesive on the Thermal Degradation of Plywood
}

\section{FATIMA KHAMMOUR $^{1 *}$, AYOUB AINANE ${ }^{1}$, MOUSSA ELMATAR $^{2}$, ABDELKBIR KENZ $^{1}$, M'HAMED ELKOUALI', MOHAMMED TALBI ${ }^{1}$ and TARIK AINANE ${ }^{1,3}$}

'Laboratory of Analytical Chemistry and Physical Chemistry of Materials, Faculty of Sciences Ben Msik, University of Hassan II, BP 7955 Casablanca 20660, Morocco.

${ }^{2}$ Technical Center for Wood and Furniture Industries, Road Ouled Haddou, Complex of Technical

Centers, Casablanca 20100, Morocco.

${ }^{3}$ Superior School of Technology - Khenifra (EST-Khenifra), University of Moulay Ismail, PB 170,

Khenifra 54000 Morocco.

*Corresponding author E-mail: khammourfatima@gmail.com

http://dx.doi.org/10.13005/ojc/340325

(Received: January 30, 2018; Accepted: March 08, 2018)

\section{ABSTRACT}

In this article, the plywood panel using a new adhesive formulation of urea formaldehyde resin is evaluated to study the effect of waste mint on the thermal behavior of plywood. The adhesive formulation was loaded by a percentage of waste mint. According to TGA and DSC results obtained by thermogravimetry and differential scanning calorimetry methods, the decomposition temperature of the above mentioned plywood panel (P-WM) is slightly higher compared to the reference plywood (P-REF). The results also show that plywood panel (P-WM) has better thermal stability characteristics than plywood panel (P-REF). The plywood panel increases the enthalpy of degradation according to DSC results.

Keywords: Adhesive formulation, Waste mint, Plywood, TGA, DSC.

\section{INTRODUCTION}

Wood is a complex material, consisting mainly of cellulose, lignin and hemicelluloses. The constituents of wood are basically a series of tubular fibers or cells cemented together. Cellulose ishighly responsible for wood strength for its linear orientation and a high degree of polymerization in wood.
Hemicelluloses act as a coupling agent to bind no ncrystalline hydrophilic cellulose and amorphoushy drophobic lignin. Cellulose, hemicellulose, and lignin are mainly responsible for mechanical properties of wood. The macromolecule of cellulose is formed by covalent bond which is resistance for tensile stress and hydrogen bonds within the cellulose provide rigidity by transferring stress. 
In outdoor applications, wood suffers from the photodegradation process 1 . The study and the understanding of the thermal decomposition of the wood, which is a determining phenomenon in the propagation of fires, require the characterization of the thermal decomposition of each one of these three main compounds constituting this material.

Hemicellulose is the least thermally stable component, since its decomposition temperature is between 200 and $325^{\circ} \mathrm{C}$ while it is for cellulose between 240 and $375{ }^{\circ} \mathrm{C}$ and between 250 and $500{ }^{\circ} \mathrm{C}$ for lignin ${ }^{2}$.

The thermal decomposition of the wood and wood composite depends on its fire-retardant chemicals and chemical modification of wood cell wall.

Phosphoric acid is one of the most uses fire retardant chemicals to reduce the number of volatiles and to increase the amount of residual char ${ }^{3}$.

Aluminum hydroxide and $\mathrm{Mg}(\mathrm{OH})_{2}$ are used as heat retardant materials for their endothermic property and their dehydration property todilute the combustible fuels and oxygen ${ }^{4}$. Silicates as heat retardants in wood composite make silica carbon compound which creates a barrier, but this residue is structurally very weak ${ }^{5}$.

The combustion of plywood has been studied, Delichatsios ${ }^{6}$ examines two types of plywood, normal and fire retardant $4 \mathrm{~mm}$ thick. He shows that the fuel mass flux atignition is nearly independent of oxygen concentration and he calculatesthe gas yields for $\mathrm{CO}, \mathrm{CO}_{2}$ and smoke.

During heat treatment, physical and chemical processes occur in layers near the surface that result in a modified surface with new characteristics?

To understand thermal degradation of wood and wood materials; TGA and DSC are traditional methods to investigate thermal degradation by determination of the weight loss characteristics at different heating rates and atmospheres ${ }^{8-9}$, and to determine the thermal energy released or absorbed via chemical reactions of the constituents during heating, which lead to the exothermic and endothermic reactions. Endothermic reactions provide information on sample melting, phase transitions, evaporation, dehydration, and pyrolysis. Exothermic reactions provide information on crystallization, oxidation, combustion, decomposition, and chemical reactions ${ }^{10}$.

On the other hand, most plywood mills usually use a urea-formaldehyde (UF) adhesive, in different adhesive formulation by adding wheat flour to urea formaldehyde glue in order to improve the performance of plywood boards.

The use of different types of fillers, such as nut shell flour, Douglas fir bark powder, alder bark powder and wood powder, is used to reduce cost of UF adhesives. It also serves to control the penetration into the wood fiber and to moderate the strength properties to suit the materials to be bonded.

It is very interesting to develop new adhesives that will replace wheat flour, nut shell flour, Douglas fir bark powder, alder bark powder and wood powderin UF glue, to improve the properties of plywood and also save wheat.

The purpose of this study is to investigate differential scanning calorimetry (DSC) and thermogravimetric (TGA) properties of two samples of plywood panels, using two different adhesive formulations by adding two types of fillers with different percentages.

\section{MATERIALS AND METHODS}

\section{Preparation of adhesive formulations and plywood samples}

The preparation of the adhesive formulations was carried out according to the following procedure.

The urea-formaldehyde resin in the form of a $51.02 \%$ aqueous solution was placed in a reactor equipped with a stirrer. The following components were added respectively to the mixture as follows: $16.33 \%$ of water, $27.04 \%$ of starch-based powder, $2.55 \%$ of urea and $3.06 \%$ of ammonium sulfate. The operation of stirring the mixture was continued until a viscous and homogeneous liquid was obtained. 
By proceeding with the same formulation as described above but with a modification of $4.59 \%$ of starch powder by mint waste dried and crushed was used in this work.

Therefore, two plywood panels (P-WM) and $(\mathrm{P}$-REF) sized $(2100 \times 1000 \times 4) \mathrm{mm}$ are created. Glue consumption was $373 \mathrm{~g} / \mathrm{m}^{2}$ in each entire panel. Panels were pressed under a specific pressure of 50 bars for 4 min. at $98^{\circ} \mathrm{C}$.

\section{Thermogravimetric Analysis (TGA)}

The apparatus used is a TA Instrument thermogravimetric analyzer BR. The nitrogen flow $\left(\mathrm{N}_{2}\right)$ is $60 \mathrm{ml} \mathrm{min}^{-1}$. The thermogravimetric analysis was applied to the sample of very small size and low mass $(m=5 \mathrm{~g})$, a temperature ramp, at a heating rate of $20^{\circ} \mathrm{C}$. $\mathrm{min}^{-1}$. between the atmospheric temperature $\left(20^{\circ} \mathrm{C}\right)$ and the maximum temperature $\left(1000^{\circ} \mathrm{C}\right)$. Changes in weight loss as a function of temperature are recorded continuously.

\section{Differential Scanning Calorimetry (DSC)}

DSC analysis is carried out to determine the thermal energy released or absorbed via chemical reactions of the plywood (P-WM) and (P-REF) constituents during heating, which lead to the exothermic and endothermic reactions.

The DSC was performed with a differential calorimetric analyzer from TA Instrument. The thermal analyzes were realized in a nitrogen gas atmosphere with a flow rate of $50 \mathrm{ml} \mathrm{min}{ }^{-1}$ at a heating rate of $20^{\circ} \mathrm{C} \mathrm{min}-1$ from $40^{\circ} \mathrm{C}$ to $300^{\circ} \mathrm{C}$. The weight of the samples was maintained at about $5 \mathrm{mg}$.

\section{RESULTS AND DISCUSSION}

\section{Characterization of Thermal Decomposition- Thermogravimetric Analysis}

The changes in weight loss during thermal decomposition of plywood (P-WM) and (P-REF) under nitrogen and air are shown in Fig. 1 and 2, respectively.

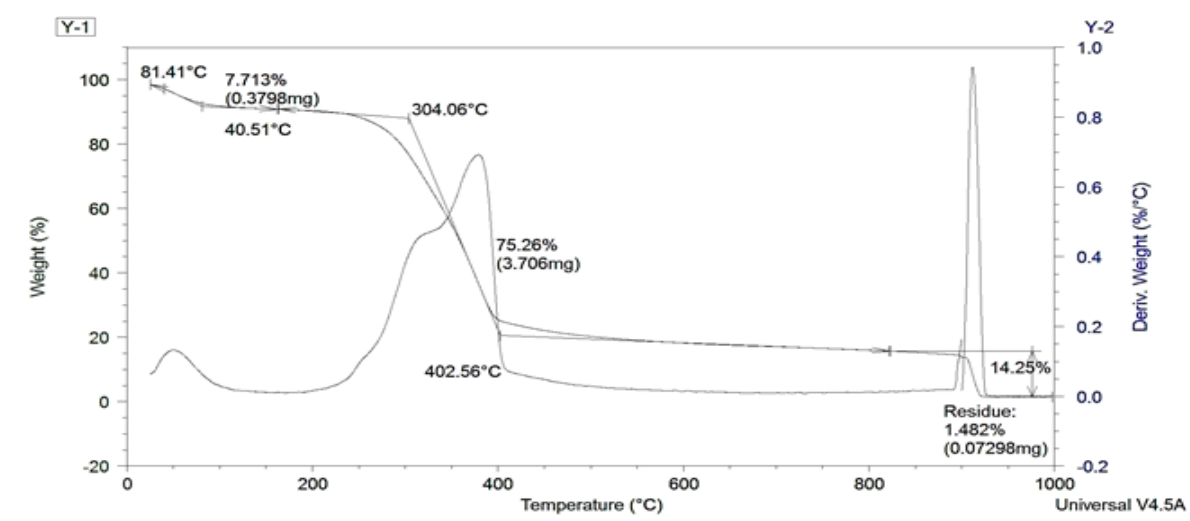

Fig. 1. Thermogram of evolutions of the weight as a function of the temperature for plywood (P-WM) in TGA

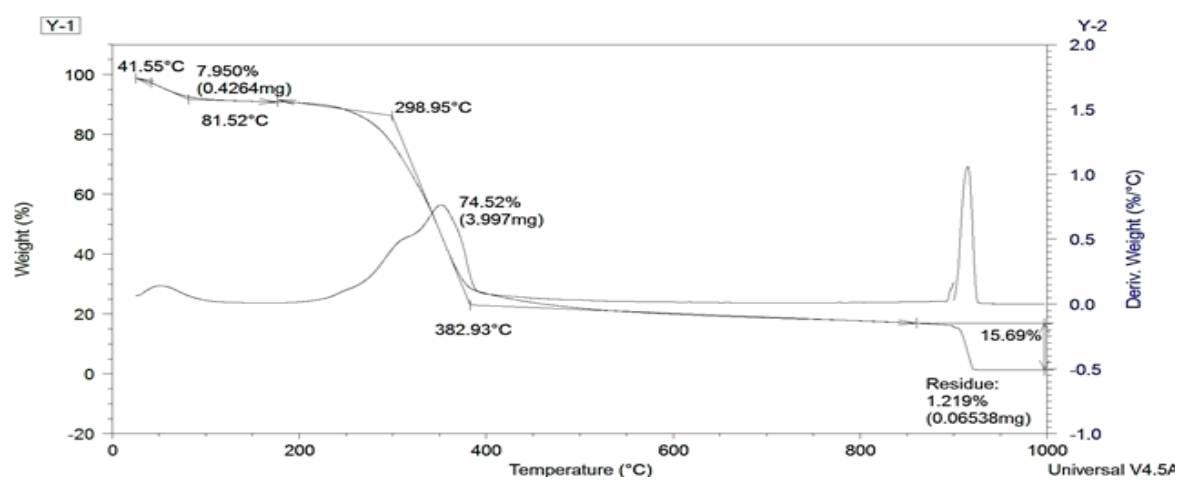

Fig. 2. Thermogram of evolutions of the weight as a function of the temperature for plywood (P-REF) in TGA 
The weight of every sample of panel was reduced with increasing temperature. From Fig. 1 and 2, we observe a first loss of mass of low intensityat the beginning of heating $\left(T<100{ }^{\circ} \mathrm{C}\right)$, then a loss of main mass with a strong intensity for a range of temperature from $200^{\circ} \mathrm{C}$ to $400^{\circ} \mathrm{C}$. For the highest temperatures, a low mass loss is shown at $\mathrm{T}>400^{\circ} \mathrm{C}$. Therefore, it seems at first sight that the decomposition of both plywood panels (P-WM) and (P-REF) under an inert atmosphere takes place in three main stages in the same temperature ranges.

The decomposition temperature of plywood (P-WM) was higher than the one of (P-REF). Three steps in the thermal decomposition of plywood (P-WM), and plywood (P-REF) could be observed. The first step degradation occurred between room temperature and $200^{\circ} \mathrm{C}$. This step was associated with the evaporation of absorbed moisture from the samples ${ }^{11}$. There are three different types of water, such as free water, loosely bonded water and chemically bonded water, in wood. As a consequence, the loss of water, as recorded by the thermo gravimetric curve, is the result of the overlapping of three different processes in which the three types of water are lost ${ }^{12}$. The initial weight loss of the samples below $100^{\circ} \mathrm{C}$ was a slightly low for plywood (P-WM) $(7.713 \%)$ compared to plywood (P-REF) $(7.950 \%)$. This may be due to the fact that adhesive formulation, loaded with a percentage of mint waste used in the panel (P-WM), forms a covalent bond with the -OH groups of wood veneer cell wall and fills the cavity of wood veneer cell wall.

The second step is observed between $200^{\circ} \mathrm{C}$ and $400^{\circ} \mathrm{C}$. This step shows that the panel $\left(\mathrm{P}\right.$-WM) $\left(\mathrm{T}^{\circ}=402.56^{\circ} \mathrm{C}\right)$ is thermally stable than the panel (P-REF) $(T=382.93)$.

This is due to the fact that adhesive formulation loaded with waste mint has a better distribution on veneer; thereby impede the passage of volatile decomposed products in the wood veneer.

On the other hand, this degradation stage corresponds to the transformation of virgin wood into active wood, as well as to the rupture of the connections between water (constitutive) and wood. The observed loss of mass is related to the degradation of the weakest chemical bonds.

This step corresponds to the devolatilization of hemicellulose and cellulose. It is also related to the decomposition of lignin, which starts at around $280^{\circ} \mathrm{C}$

At $400{ }^{\circ} \mathrm{C}$ and under nitrogen, it is the end of the thermal decomposition and the formation of char. In air, an additional step is observed between $400^{\circ} \mathrm{C}$ and $600^{\circ} \mathrm{C}$, corresponding to the oxidation of char. Thus, beyond $600^{\circ} \mathrm{C}$, the end of the oxidation process leads to different residual masses for the two panels, such as the panel (P-WM) has a residual mass of $0.073 \mathrm{mg}$ while the panel (P-REF) has a residual mass of $0.065 \mathrm{mg}$.

\section{Characterization of Thermal Decomposition- Differential scanning calorimetry}

Figures 3 and 4 show the plywood DSC curves (P-WM) and (P-REF). We notice an endothermic peak around $109.9{ }^{\circ} \mathrm{C}$ for plywood (P-WM) which corresponds to the evaporation of the water absorbed by the plywood panel. Around $110^{\circ} \mathrm{C}$ and $120^{\circ} \mathrm{C}$, the enthalpy of degradation $(210.8 \mathrm{~J} / \mathrm{g})$ of the plywood panel (P-WM) was higher compared to the plywood panel (P-REF) $(202.4 \mathrm{~J} / \mathrm{g})$. This is due to the formation of better interfacial adhesion between the adhesive formulation loaded by the mixture $(22.45 \%$ of starch-based powder $+4.59 \%$ of mint waste) and the plywood veneers. Another endothermic peak observed for (P-WM) and (P-REF) at $251.75^{\circ} \mathrm{C}$ and $247.92^{\circ} \mathrm{C}$ respectively. This is due to the devolatilization of hemicelluloses.

The endothermic peak observed around $344.67{ }^{\circ} \mathrm{C}$ for plywood (P-WM) and $341.23{ }^{\circ} \mathrm{C}$ for plywood (P-REF), indicates the degradation of cellulose, leading to carbonization.

The two peaks show there was little change in the decomposition temperature of plywood in DSC. The increase in cellulose and hemicellulose degradation temperature for plywood (P-WM) indicates that using a percentage of mint waste as filler in urea formaldehyde resin could affect the decomposition behavior plywood. 


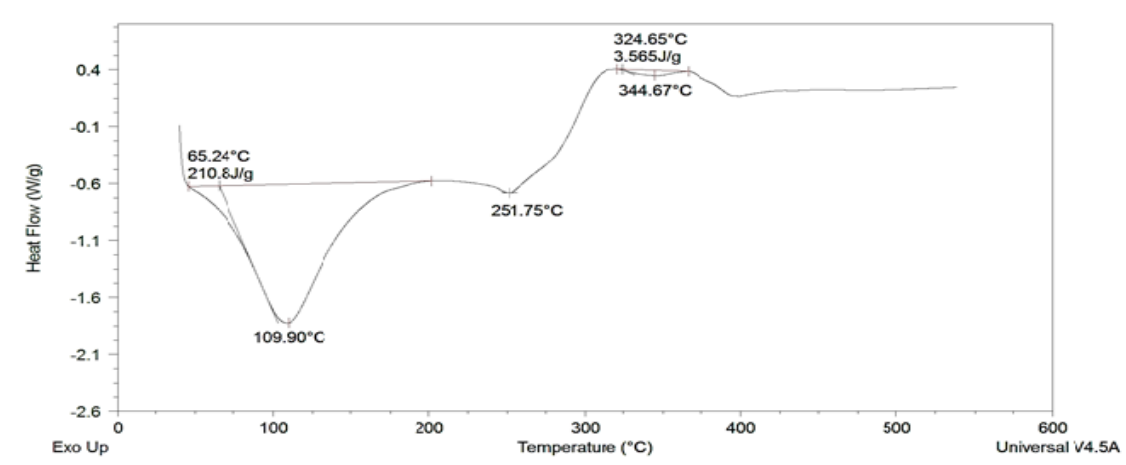

Fig. 3. Thermogram of heat flow evolutions as a function of temperature for plywood (P-WM) in DSC

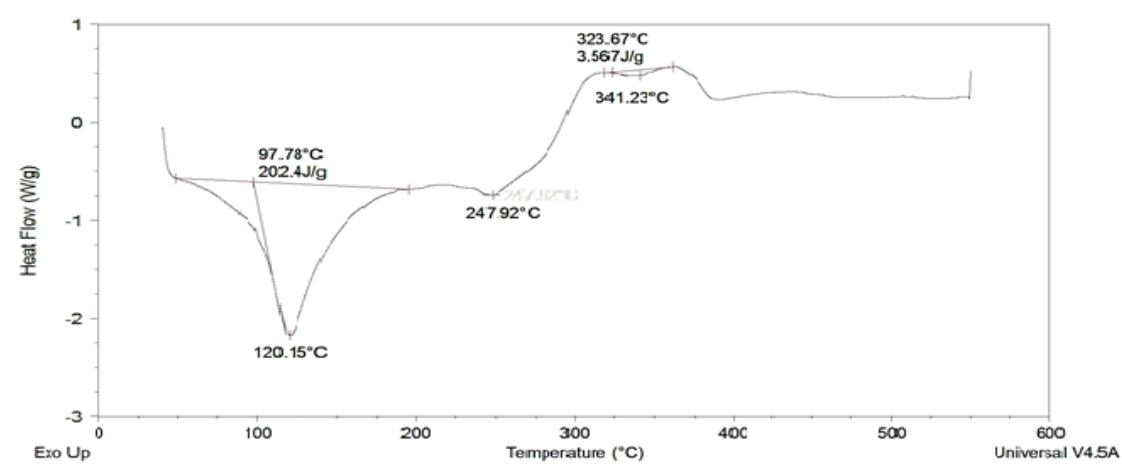

Fig. 4. Thermogram of heat flow evolutions as a function of temperature for plywood (P-REF) in DSC

\section{CONCLUSION}

The addition of $4.59 \%$ mint waste as filler in the urea formaldehyde resin has improved the thermal behavior of plywood.

According to TGA results, little differences were observed in the decomposition temperature of the plywood. For instance, while the plywood decomposition temperature is increasing, the plywood is thermally stabilized.
As results of DSC, the degradation of plywood constituents (cellulose and hemicelluloses) and the enthalpy of degradation were high compared to the reference plywood.

\section{ACKNOWLEDGEMENT}

The authors thank heartily University of Hassan II Casablanca, Technical Center for Wood and Furniture Industries (CTIBA) and University of Moulay Ismail Meknes for their guidance and support.

\section{REFERENCES}

1. Mattos, B.D; Cademartori, P.H.G.D; Lourencon, T.V; Gatto, D., Int. Wood Prod. J. 2014, 5, 33-38.

2. DI BLASI, C. Progress in Energy and Combustion Science., 2008, 34, 47-90.

3. Baysal, E. African J. Biotech., 2011, 10, 19255-19260.

4. Garcia, M; Hidalgo, J ; Garmendia, I; GarcíaJaca, J. Compos., 2009, 40, 1772-1776.

5. Xu, B; Ding, J; Feng, L; Ding, Y; Ge, F; Cai, Z. Surf. Coat. Technol., 2015, 262, 70-76.

6. Hagen, M; Hereid, J; Delichatsios, M.A; Zhang, J; Bakirtzis, D. Fire Safety Journal., 2009, 44, 1053-1066.
7. Candan,Z; Buyuksarı, U; Korkut, S; Unsal, O; Cakıcıer, N. Industrial Crops and Products. 2012, 36, 434-436.

8. Mehrabian,R; Scharler, R; Obernberger, I. Fuel, 2012, 93, 567-575.

9. Richard, W.C; Mark, A.S; Anal. Chim. Acta., 2009, 639, 62-66.

10. Rahman, M.R; Hamdan, S; Ahmed, A.S. Journal of Vinyl and Additive Technology., 2011, 17, 177-183.

11. Liu, Z; Jiang, Z; Fei, B; Liu, X. Bio Res., 2013, 8, 5014-5024.

12. Forouharshad, M; Montazer, M; Moghadam, M.B; Saligheh, O. Thermo chim. Acta., 2011, 516, 29-34. 